for diatomics substantial progress has been achieved, as evidenced by some of the present papers.

Lastly, the symposium did achieve its major goal: to bring experimentalists and theorists together and to show that the field of thermal elementary reaction kinetics is alive and well.

\title{
Kinetic Measurements Using Flow Tubes
}

\author{
Carleton J. Howard \\ Aeronomy Laboratory, NOAA Environmental Research Laboratory, Boulder, Colorado 80303 (Received October 6, 1978) \\ Publication costs assisted by the NOAA Environmental Research Laboratory
}

This paper is a selective survey of the chemical kinetic literature involving flow tube measurements of elementary reaction rate constants. It describes the origins of the flow tube method, the experimental technique, the measurement of rate constants, and an analysis of the inherent errors. Emphasis is placed on the discussion of the strengths and limitations of the method as a source of kinetic data.

\section{Introduction}

In recent years there has been an increasing demand for gas phase reaction rate data. Laser development, ${ }^{1}$ atmospheric chemistry, ${ }^{2,3}$ and combustion ${ }^{4}$ are examples of fields of application of elementary reaction studies. Committees and organizations have been created to collect, evaluate, and disseminate kinetic information. In atmospheric chemistry, for example, there are serious economic and social implications derived from the application of kinetic data in computer models that assess the impact of anthropogenic chemicals on stratospheric ozone. Thus, increased concern for the accuracy of rate constant measurements has developed concurrently with the demand for more data.

The flow tube technique has been the most prolific source of kinetic data near $300 \mathrm{~K}$. In evaluating the usefulness of this method for obtaining rate constant data it is instructive to make a comparison with the flashphotolysis technique. This comparison on the basis of seven different criteria is summarized in Table I. The emphasis of this discussion is not to demonstrate the superiority of one method in all categories but rather to show the complementary nature and strengths of both methods. In making such a comparison it is necessary to make some generalizations that are not accurate for every study. In this respect the discussion is influenced by the experiences we have had in the NOAA Aeronomy Laboratory using both techniques.

A. Temperature Range. The useful temperature range is nearly the same for both techniques. The upper temperature limit is established by the onset of problems with the thermal stability of reactants and the selection of materials for fabricating the apparatus. At the low temperature extreme the flow tube method is somewhat more restricted than the flash-photolysis method because of heterogeneous reactions. It is often observed that the rate of destruction of radicals such as $\mathrm{Cl}, \mathrm{OH}$, and $\mathrm{HO}_{2}$ on the reactor surface increases significantly at temperatures below about $250 \mathrm{~K} .{ }^{5}$ Nevertheless, there have been several studies using flow tube techniques beyond these limits. For example, Trainor et al. ${ }^{6}$ have studied the recombination of atomic hydrogen down to $77 \mathrm{~K}$, Westenberg and deHaas ${ }^{7,8}$ have routinely studied reactions of $\mathrm{O}$ and $\mathrm{OH}$ up to $1000 \mathrm{~K}$, and Fontijn et al. ${ }^{9}$ have developed a flow reactor designed for operation up to $2000 \mathrm{~K}$. The latter
TABLE I: Comparison of Flow Tube and Flash-Photolysis Kinetic Techniques

\begin{tabular}{|c|c|c|}
\hline & flow tube & flash photolysis \\
\hline $\begin{array}{l}\text { temperature } \\
\text { range }\end{array}$ & $200-600 \mathrm{~K}$ & $100-600 \mathrm{~K}$ \\
\hline $\begin{array}{l}\text { pressure } \\
\text { range }\end{array}$ & $1-10$ torr & $\begin{array}{l}5 \text { torr-several } \\
\text { atmospheres }\end{array}$ \\
\hline $\begin{array}{l}\text { rate constant } \\
\text { range }\end{array}$ & $\begin{array}{c}\left(10^{-10}-10^{-16}\right) \mathrm{cm}^{3} \\
\text { molecule }^{-1} \mathrm{~s}^{-1}\end{array}$ & $\begin{array}{c}\left(10^{-10}-10^{-18}\right) \mathrm{cm}^{3} \\
\text { molecule } \\
-1\end{array}$ \\
\hline & excellent & $\begin{array}{l}\text { requires fast } \\
\text { detector }\end{array}$ \\
\hline $\begin{array}{l}\text { reactant } \\
\text { versatility }\end{array}$ & excellent & limited \\
\hline $\begin{array}{l}\text { heterogeneous } \\
\text { reactions }\end{array}$ & can be serious & none \\
\hline expense & low & moderate \\
\hline
\end{tabular}

work deals with reactions of metals and metal oxides in a special application of the flow tube technique and is described in detail elsewhere in this volume. ${ }^{10}$

B. Pressure Range. The flow tube technique is basically a low pressure technique as will be discussed later. Flash photolysis, on the other hand, can be used to very high pressures with the main limitation being the detection of reactants. If resonance fluorescence is used for detection, some species such as $\mathrm{OH}$ are quenched by the buffer gas. In this case resonance absorption may be used ${ }^{11}$ to extend the pressure range.

C. Rate Constant Range. Both flow tube and flashphotolysis techniques are used to measure fast reactions with rates up to gas kinetic collision rates. The greater pressure range of the photolysis method also allows larger reactant concentrations to be used and hence smaller rate constants to be measured. Thus photolysis systems have a significant advantage for studying slow reactions and termolecular reactions at high pressures.

D. Detector Versatility. One of the two major advantages of the flow tube technique is the immense variety of methods that can be used to detect the reactants and products. This advantage is derived from the steady-state nature of the flow system in which the progress of the reaction is frozen at any fixed observation point along the tube. Since the concentrations of the reactants are constant at that point, there are no constraints on the detector speed. A flash-photolysis experiment, on the other hand, is studied in real time and requires a detector 
with a time resolution that is at least $1 / 10$ the period of the experiment, i.e., in the millisecond range. Low signal levels can be overcome using signal averaging techniques ${ }^{12,13}$ but some detectors such as magnetic resonance methods cannot be applied to flash-photolysis experiments.

E. Reactant Versatility. The second major advantage of the flow tube method is the great versatility it provides for working with a wide variety of reactants. With the flow tube method it is possible to generate two different labile reactants in isolation and to study their reactions under carefully controlled conditions. For example, reactions such as $\mathrm{HO}_{2}+\mathrm{ClO} \rightarrow \mathrm{HOCl}+\mathrm{O}_{2},{ }^{14} \mathrm{O}+\mathrm{ClO} \rightarrow \mathrm{Cl}+\mathrm{O}_{2},{ }^{15}$ and $\mathrm{N}+\mathrm{OH} \rightarrow \mathrm{NO}+\mathrm{H}^{16}$ have been studied in flow tubes. Titration reactions, which will be described later, play an important role in the reactant versatility of the flow tube, since they make it possible to produce accurately known concentrations of labile reactants.

The flash-photolysis technique is limited by the requirement of photolytic generation of the radical reactant. This factor is a restriction on both reactants because some gases such as $\mathrm{NO}_{2}$ and $\mathrm{O}_{3}$ are also dissociated by the flash radiation and may produce unwanted reactive fragments.

F. Heterogeneous Reactions. An important advantage of the flash-photolysis experiment is that it can be conducted at the center of a larger reactor, far removed from the walls and the possibility of heterogeneous reactions. Heterogeneous chemistry is observed to interfere in the study of both bimolecular ${ }^{17}$ and termolecular ${ }^{18}$ reactions. The reactor surface can also be an impediment to studying reactions of vibrationally or electronically excited reactants because of its high deactivation efficiency. Although innovative studies of reactions of vibrationally excited $\mathrm{OH}^{19}$ and metastable $\mathrm{N}\left({ }^{2} \mathrm{D}\right)^{20}$ have been made in flow tubes, the photolysis technique is generally superior for this type of study.

G. Expense. Although this consideration is seldom examined, there can be a significant difference between a flow tube system and a flash-photolysis system in initial expenditure. A major component that contributes to this difference is the multichannel analyzer that is normally used to do time-resolved signal averaging. By using a simple detection scheme such as chemiluminescence, a flow tube kinetic system can be assembled relatively cheaply.

\section{Origins and Development of the Flow Tube Method}

The purpose of this section is to provide a brief history of the flow tube with emphasis on the developments that have contributed most to its application as a kinetic tool.

The flow tube kinetic method has evolved from the early discharge tube studies of Wood and Bonhoeffer. A major discovery of these pioneers was that large concentrations of atoms and simple radicals were generated in low pressure gas discharges. Their goal was generally to identify and characterize the sources of radiation that were emitted by the discharged gases but frequently the physics and chemistry of production and destruction of the transient species were discussed.

Wood ${ }^{21}$ was the epitome of the one man research institutions that revolutionized experimental science in the early 1900 's. He experimented with resonance fluorescence in metal atoms $\mathrm{s}^{22,23}$ and used the expressions resonance fluorescence and photoluminescence to describe the process of excitation and re-emission of resonant radiation. ${ }^{24}$ Wood applied the method only to spectroscopic problems. In 1967 Braun and Lenzi ${ }^{20}$ were the first to adapt resonance fluorescence to a flash-photolysis kinetic experiment. It has subsequently become one of the most powerful kinetic tools, particularly through the use of laser light sources.

Wood also discovered that certain materials became incandescent when exposed to the products of a hydrogen discharge. ${ }^{26}$ He deduced that the glow was due to energy released by the surface-catalyzed recombination of radicals produced in the discharge. This discovery was a primitive ancestor of catalytic probes used to measure atom concentrations in numerous flow tube kinetic studies. ${ }^{6,27-29}$

The first flow tube kinetic measurements were made in the late 1920 's. In 1929 Smallwood $^{30}$ reported measurements of the rate of recombination of hydrogen atoms. $\mathrm{He}$ employed a Wood-Bonhoeffer type discharge tube as a source of atomic hydrogen and a moveable catalytic probe inspired by Wood's "incandescent wire" experiment (both Wood and Smallwood were at The Johns Hopkins University). The atom concentration in the flow tube was measured using a calorimeter attached to the outside of the flow tube. Smallwood calculated both homogeneous and heterogeneous recombination rate constants using an analysis similar to the modern method described later.

At about the same time in Germany, chemists following the leadership of Bonhoeffer ${ }^{31}$ were also making kinetic measurements in discharge-flow systems. An important step in this development was the invention of the Wrede-Harteck gauge ${ }^{32}$ a simple device for measuring the partial pressure of atoms in a discharged gas mixture. Harteck and Kopsch ${ }^{33}$ studied the reactions of atomic oxygen with 22 different compounds including $\mathrm{H}_{2}, \mathrm{CO}$, $\mathrm{H}_{2} \mathrm{~S}, \mathrm{CS}_{2}, \mathrm{NH}_{3}, \mathrm{HCl}$, and numerous hydrocarbons. The atomic oxygen was produced by an ac discharge and its concentration was estimated using a Wrede-Harteck gauge and a hot platinum wire. The relative reactivities of the reactants were determined qualitatively by spectroscopic measurements of chemiluminescent emissions from the reaction zone and by trapping and analyzing the final products.

In the late 1950's and early 1960's several important advances were made in flow tube techniques and instrumentation. Much of our present technology can be traced to these developments.

A paper by Kaufman ${ }^{34}$ in 1958 made two major contributions to flow tube kinetics. He studied the kinetics of the air afterglow reaction

$$
\mathrm{O}+\mathrm{NO} \rightarrow \mathrm{NO}_{2}+h \nu
$$

and demonstrated that the intensity of the chemiluminescence is proportional to the concentrations of atomic oxygen and nitric oxide, i.e., $I \propto[\mathrm{O}][\mathrm{NO}]$. This discovery provided a sensitive quantitative detection method for small concentrations of atomic oxygen. The second contribution was the observation that the reaction

$$
\mathrm{O}+\mathrm{NO}_{2} \rightarrow \mathrm{NO}+\mathrm{O}_{2}
$$

was extremely fast and could be used as a gas phase titration to measure atomic oxygen concentrations in a flow tube. The endpoint of the titration was indicated by the extinction of the airglow emission. Kaufman applied these techniques to study some atomic oxygen reactions.

Kaufman and co-workers also introduced two other important titration schemes

$$
\mathrm{N}+\mathrm{NO} \rightarrow \mathrm{O}+\mathrm{N}_{2}^{35}
$$

and

$$
\mathrm{H}+\mathrm{NO}_{2} \rightarrow \mathrm{OH}+\mathrm{NO}^{36}
$$

The importance of the titration methods cannot be overemphasized because they provide the foundation for nearly all kinetic measurements in flow systems. They are 
fast stoichiometric reactions that provide cleanly quantitative methods of preparing labile species. The concept of gas phase titrations has now been extended to many different atomic and simple radical species. Clyne has been instrumental in developing numerous useful titration schemes and recently reviewed many of them. ${ }^{37,38}$

The use of chemiluminescence as a flow tube reaction rate diagnostic has also been widely extended. For example, Clyne and Thrush ${ }^{39}$ developed a UV detector for atomic oxygen using $\mathrm{CO}$ and Setser and co-workers ${ }^{40}$ reported an IR chemiluminescent detector for studying hydrogen abstraction reactions of atomic fluorine.

There were two major developments in instrumentation that helped to establish the early dominance of the flow tube method in the field of gas kinetics. These were mass spectrometry ${ }^{41}$ and electron paramagnetic resonance $(\mathrm{EPR})^{42}$ or electron spin resonance (ESR). Foner and Hudson $^{43,44}$ and Phillips and Schiff ${ }^{45}$ were the first to combine mass spectrometer detectors with flow tubes for kinetic measurements. Subsequently, this combination has been successfully exploited in a wide variety of kinetic applications. ${ }^{46-50}$ The mass spectrometer has potential as a universal detector but lacks in selectivity due to the fragmentation and ionization of all gases present in the ion source. This problem has been significantly reduced by two innovations: photoionization ion sources and magnetic deflection of neutrals. Jones and Bayes ${ }^{51,52}$ and Gutman and co-workers ${ }^{53,54}$ were among the first to apply photoionization to gas kinetics. Kaufman and co-workers ${ }^{55,56}$ have used an inhomogeneous magnetic field to separate the paramagnetic species (radicals) from the diamagnetic background gas and to selectively deflect the paramagnetic species into a mass spectrometer. The sensitivity of mass spectrometers varies greatly for different systems and different molecules but concentrations down to about $10^{9}$ molecules $\mathrm{cm}^{-3}$ can be detected.

EPR can be used to detect only paramagnetic species, but fortunately that encompasses most atoms and simple radicals. The first kinetic measurement with EPR was reported by Krongelb and Strandberg ${ }^{57}$ in a study of atomic oxygen recombination. Westenberg and deHaas ${ }^{58,59}$ have been leaders in its application to flow tube gas kinetics and have reported studies on a wide variety of species including $\mathrm{H}, \mathrm{O}, \mathrm{N}, \mathrm{Cl}$, and $\mathrm{OH}$. Several other laboratories have also recently made major contributions to this field. ${ }^{46,60,61}$ The detection limit for EPR is about $10^{11}$ molecules $\mathrm{cm}^{-3}$.

Resonance absorption has been employed in both the UV and vacuum UV wavelength regions as a detection method in flow tube kinetic studies. This technique is sensitive and very selective. Kaufman used UV resonance absorption in the first flow tube study of the kinetic sources and chemistry of OH radicals. ${ }^{36}$ Later work in his laboratory used vacuum UV absorption to study atomic species in flow tubes. ${ }^{20}$ There are a few examples of studies where resonance absorption is still superior to other detection methods (such as in the study of atomic fluorine reactions), ${ }^{62}$ but resonance fluorescence to a great extent has supplanted this technique. Resonance fluorescence is routinely used to detect atoms and radicals at concentrations as low as $10^{9}$ molecules $\mathrm{cm}^{-3}$ in flow tube studies. ${ }^{14,18,37}$

A new era in flow tube kinetics has been introduced by the application of sensitive detection techniques such as mass spectrometry, resonance fluorescence, and laser magnetic resonance. ${ }^{63}$ With these detection methods, measurements are made at low radical concentrations $\left(<10^{11}\right.$ molecules $\left.\mathrm{cm}^{-3}\right)$ so that interference from sec-

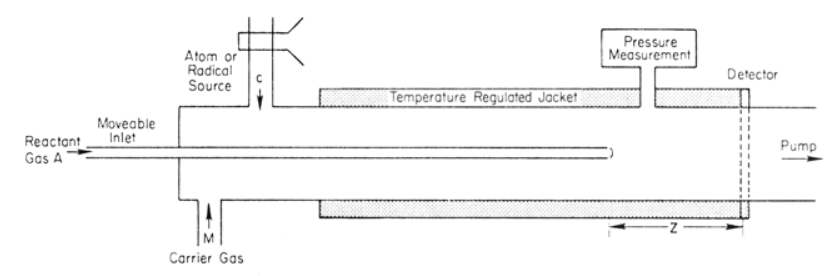

Figure 1. Schematic of flow tube apparatus.

ond-order reactions and secondary chemistry becomes negligible. The suppression of secondary reactions of products and intermediates eliminates a major source of error in kinetic measurements.

In conclusion, we now have an assortment of methods for producing accurately measured concentrations of reactants and for detecting low concentrations of atoms and radicals. The next section reviews the measurement and analysis procedures used to determine the rate constants.

\section{Technique and Analysis}

A schematic of a flow tube reactor is shown in Figure 1. The major component is a glass tube usually about 2.5 $\mathrm{cm}$ i.d. and $1 \mathrm{~m}$ long. The section of the reactor on the right is the reaction zone and is surrounded by a temperature regulated jacket that allows a constant temperature to be maintained anywhere from about 200 to 600 K.

The carrier gas (M) enters the flow tube at the left. This gas is the major component in the flow tube and thus serves to define the physical properties of the gas stream, e.g., pressure, flow velocity, heat capacity, thermal conductivity, viscosity, etc. It also acts as a heat bath to maintain the reactants at the temperature of the walls of the reactor, controls diffusion, and serves as a third body in termolecular reactions. Helium is a common choice as a carrier gas because of its inertness, high thermal conductivity, and excellent diffusion coefficients.

Atomic reactants are usually generated in electrodeless microwave discharges or by thermal dissociation. The microwave discharge system is the more common method since the development of simple and compact cavities. ${ }^{64}$ Langmuir ${ }^{65}$ developed an apparatus for producing atoms by thermal dissociation which is a very clean method, but is seldom used in flow systems. ${ }^{6,27}$ The advantage of thermal dissociation is that the method is much more discriminating than an electrical discharge. While a discharge will fragment nearly any type of molecule, ${ }^{66}$ a thermal source tends to break only the weakest bonds. Thus small impurities of $\mathrm{H}_{2} \mathrm{O}, \mathrm{N}_{2}$, and $\mathrm{O}_{2}$ can be tolerated in a thermal source but will give a mixture of atomic products in a discharge source. Thermal sources are useful for generating hydrogen and halogen atoms.

Atoms from the discharge or thermal source can be used directly or can be converted to a different atomic or radical species by a titration reaction. ${ }^{34-38}$ It is important to employ different radical sources when possible to test for interference from excited states or secondary reactions.

The radical reactant enters the flow tube at a port downstream from the carrier gas entrance. A small flow of $\mathrm{He}$ or $\mathrm{Ar}$ is added to flush the gas through the radical source. The flow tube is often treated with a wall coating or poison to inhibit the removal of radicals on the tube surface. ${ }^{67}$ Phosphoric acid, boric acid, sulfuric acid, and various dry polymeric materials ${ }^{68}$ have been used effectively. Wall coatings are a black art and most laboratories have their own magic elixir.

The pressure port is located at the center of the reaction zone to minimize errors and corrections due to the pressure 
gradient in the flow tube. Care must be taken that the pressure port is smooth and oriented at right angles to the gas flow in order to measure only the static pressure in the flow tube.

Flow tube kinetic measurements usually are made by varying the reaction zone length $(z)$, that is the distance to the detector from the point at which the two reactants are mixed. This can be accomplished by changing the position of the detector or the reactant inlet. Moveable detectors were used in some studies ${ }^{6,30,36}$ as were moveable discharge sources. Most flow tube systems now employ either a series of fixed, valved ports along the flow tube ${ }^{69}$ or a moveable injector ${ }^{70}$ as shown in Figure 1. The fixed inlets are short and therefore have an advantage if the added reactant is very reactive and destroyed by wall collisions or by gas recombination. The moveable inlet on the other hand requires fewer connections through the flow tube temperature jacket and allows greater flexibility in varying the reaction zone length. Both methods have been used to add reactive species such as $\mathrm{O}, \mathrm{N}, \mathrm{H}, \mathrm{HO}_{2}$, and $\mathrm{ClO}$. The exit orifice on the moveable inlet consists of a series of small holes around the diameter of the tube. The purpose of this configuration is to provide rapid mixing of the added gas with the carrier stream. The added reactant is assumed to be thoroughly mixed with the carrier gas.

A great variety of detectors can be used with the flow tube. The most important requirement of the detector is that it be sensitive. For best results the concentration of the radical species, $c$, should be less than about $10^{11}$ molecules $\mathrm{cm}^{-3}$ when radical-molecule reactions are studied. The concentration of the added reactant, $A$, is much larger, typically in the range $10^{12}-10^{16}$ molecules $\mathrm{cm}^{-3}$. Thus the reaction becomes pseudo-first order in $c$ and the rate equation is

$$
\mathrm{d} c / \mathrm{d} t=-k c
$$

The first-order rate constant $k\left(\mathrm{~s}^{-1}\right)=k^{\mathrm{II}} A$, where $k^{\mathrm{II}}$ is the second-order rate constant $\left(\mathrm{cm}^{3}\right.$ molecule $\left.{ }^{-1} \mathrm{~s}^{-1}\right)$ and $A$ is the concentration of the added reactant (molecule $\mathrm{cm}^{-3}$ ). When all of the processes affecting $c$ are first order, only relative concentrations of $c$ need to be measured.

The basic assumption of the flow tube analysis is that the radical reactant is mixed homogeneously with the carrier gas and that there are no concentration gradients. Then the carrier gas flow velocity, $v$ (typically 300-2000 $\mathrm{cm} \mathrm{s}^{-1}$ ), is the transport velocity of the radicals. With this assumption the reaction time in the flow tube, $t=z / v$, is the time that the radicals and reactants are in contact from the point of addition of the reactant to the point of detection. Thus, reaction time and distance are equivalent in the flow system.

A rate constant measurement is made by measuring the radical concentration with the moveable inlet at several different positions, typically at $10-\mathrm{cm}$ intervals between $z=10$ and 50 while the reactant flow rate is held constant. These data are plotted $\ln c$ vs. $z$ and the slope is used to calculate the pseudo-first-order rate constant

$$
k=-v \frac{\mathrm{d}(\ln c)}{\mathrm{d} z}
$$

The bimolecular rate constant is

$$
\begin{aligned}
k^{\mathrm{II}}=-\frac{F_{\mathrm{T}}{ }^{2}}{F_{\mathrm{A}}} \frac{T^{2}}{273^{2}} \frac{760^{2}}{P_{\mathrm{T}}^{2}} \frac{1}{2.69 \times 10^{19} \pi R^{2}} \times \\
\frac{\mathrm{d}(\ln c)}{\mathrm{d} z} \mathrm{~cm}^{3} \text { molecule }^{-1} \mathrm{~s}^{-1}
\end{aligned}
$$

where $F_{\mathrm{T}}$ and $F_{\mathrm{A}}$ are the total and reactant flow rates (STP $\left.\mathrm{cm}^{3} \mathrm{~s}^{-1}\right), T$ is the temperature $(\mathrm{K}), P_{\mathrm{T}}$ is the total pressure (torr), and $R$ is the flow tube radius $(\mathrm{cm})$.

With most radical reactants there is a significant first-order loss at the reactor wall. The fraction of wall collisions that remove the radicals is $\gamma$. The number of radical destroying wall collisions per unit area is given by gas kinetic theory: $1 /{ }_{4} \gamma \omega c$, where $\omega$ is the average molecular speed. Thus the rate of removal of radicals by wall collisions is given by

$$
\frac{\mathrm{d} c}{\mathrm{~d} t}=\frac{1}{4} \gamma \omega c \frac{S}{V}
$$

where $S / V$ is the surface-to-volume ratio of the cylindrical reactor $=2 / R$. This rate defines the first-order rate constant $k_{\mathrm{w}}$

$$
k_{\mathrm{w}}=\gamma \omega /(2 R) \mathrm{s}^{-1}
$$

Clyne and Thrush ${ }^{69}$ and Westenberg and deHaas ${ }^{70}$ have demonstrated the advantage of the variable reaction zone length method of analysis by showing that the rate constants derived by this method are not affected by wall reactions. The radical concentration at the detector a fixed distance $l$ from the radical source is $c=c_{0} \exp \left\{-k_{\mathrm{w}} l / v\right\}$, where $c_{0}$ is the initial radical concentration. When reactant $A$ is added at a distance $z$ from the detector, the detected radical concentration is

$$
c=c_{0} \exp \left\{-k_{\mathrm{w}} l / v\right\} \exp \{-k z / v\}
$$

Thus the wall reaction term is constant and independent of the $z$-dependent reaction term if $\gamma$ is unchanged in the presence of added reactant. A plot of $\ln c$ vs. $z$ witl have a slope, $\mathrm{d} \ln c / \mathrm{d} z=-k / v$.

Westenberg and deHaas ${ }^{70}$ also demonstrated in their analysis that the detector may be outside the temperature-controlled region. This is equivalent to having a poorly defined absolute reaction length, e.g., as results from a change in flow tube diameter at the intersection with the detector. Since the rate constant is derived from the slope, it can be shown that accurate measurements are required only of the relative radical concentration, of the $\Delta z$ increments, and of absolute reactant concentration $(A)$.

It is useful to estimate the precision expected in measurements of rate constants using eq 6 . This requires estimates of the precision in the measurement of each of the variables in the calculation and a standard propagation of errors analysis of the equation. ${ }^{71}$ The result is

$$
\begin{aligned}
\frac{\Delta k^{\mathrm{II}}}{k^{\mathrm{II}}}= & {\left[\left(2 \frac{\Delta F_{\mathrm{T}}}{F_{\mathrm{T}}}\right)^{2}+\left(2 \frac{\Delta T}{T}\right)^{2}+\left(\frac{\Delta F_{\mathrm{A}}}{F_{\mathrm{A}}}\right)^{2}+\right.} \\
& \left.\left(2 \frac{\Delta P_{\mathrm{T}}}{P_{\mathrm{T}}}\right)^{2}+\left(2 \frac{\Delta R}{R}\right)^{2}+\left(\frac{\Delta \text { slope }}{\text { slope }}\right)^{2}\right]^{1 / 2}
\end{aligned}
$$

The last term is the estimated precision in determining the slope $\mathrm{d}(\ln c) / \mathrm{d} z$. Reasonable estimates of the precision (95\% confidence limits) of each of the variables are $\Delta F_{\mathrm{T}} / F_{\mathrm{T}}=0.03, \Delta T / T=0.01, \Delta F_{\mathrm{A}} / F_{\mathrm{A}}=0.03, \Delta P_{\mathrm{T}} / P_{\mathrm{T}}=$ $0.01, \Delta R / R=0.01$, and $\Delta$ slope $/$ slope $=0.02$. The resultant precision in measurement of $k^{\mathrm{II}}$ is $\Delta k^{\mathrm{II}} / k^{\mathrm{II}}=8 \%$. Rate constant measurements generally have a corresponding precision in the range $5-20 \%, 17,72$

This analysis ignores two important factors: (1) the contribution of errors due to the temperature dependence of $k^{\mathrm{II}}$ and (2) the contributions of systematic errors. Cvetanovic et al. ${ }^{71}$ and Fontijn and Felder ${ }^{10}$ give analyses of the effect of the temperature dependence of the rate constant on the error analysis. The magnitude of the contribution depends on the activation energy and will not be discussed here. Systematic errors are very difficult to 
evaluate but are important because they determine the accuracy. Consideration of possible systematic errors in calibrations and measurements gives an estimated accuracy in the range of $10-15 \%$.

\section{Limitations of Flow Tube Reactors}

One of the first detailed discussions of the limitations of flow tube reactors was given by Kaufman ${ }^{73}$ in 1961 . He enumerated the basic problems arising from viscous flow and diffusion. Although these factors are important, they are frequently ignored. The most common error is to neglect the effects of concentration gradients. This section will describe the origins of the limitations and methods to minimize and correct for errors.

The flow through the reactor is fully developed viscous flow. ${ }^{74}$ The forces moving the gas develop a pressure gradient along the length of the tube. Under conditions of high flow velocities this gradient can be significant in small tubes ${ }^{73}$

$$
\Delta P / \Delta z=5.9 \times 10^{-3} \eta v / R^{2} \text { torr } \mathrm{cm}^{-1}
$$

$\eta$ is the gas viscosity $\left(\mathrm{g} \mathrm{cm}^{-1} \mathrm{~s}^{-1}\right), v$ is the flow velocity, and $R$ is the tube radius. Since gas viscosities increase with temperature, the gradients will be larger at high temperatures. The gas maintains a parabolic velocity profile

$$
v(r)=2 v\left(1-r^{2} / R^{2}\right)
$$

where $r$ is the radial parameter. Since the gas velocity is maximum at the center of the tube, the moveable inlet seriously disrupts the velocity profile. The pressure gradient is nearly twice the value obtained by eq 11 when a $3-\mathrm{mm}$ o.d. injector is present in a $25-\mathrm{mm}$ i.d. flow tube. ${ }^{75}$ The pressure gradient produces corresponding velocity and concentration gradients. These effects are normally negligible when the pressure is measured at the center of the reaction zone.

Since the viscosity has a positive temperature coefficient, the velocity profile is also disrupted when the gas enters a heated or cooled region. However, this effect is small compared to the time required for the reactants to become equilibrated. ${ }^{76}$ The solution to this problem is to allow adequate time (distance) for the reactants to enter the temperature-regulated section before mixing. About $15-20$ $\mathrm{ms}(15-20 \mathrm{~cm})$ is sufficient in a $2.5-\mathrm{cm}$ i.d. reactor operating in the usual temperature range.

At low pressures ( $<1$ torr) the velocity profile may be modified by slip, i.e., molecular flow. ${ }^{77}$ The condition for this effect to be negligible is $\lambda<R R$ ( $\lambda$ is the mean free path). Slip causes the flow velocity to be greater than zero at the wall and thereby flattens the parabolic profile. Fortunately, the velocity profile is not a factor in the analysis when there are no radical concentration gradients.

In the preceding analysis we assumed that there are no concentration gradients and that the flow velocity is the transport velocity of the reactants. Whenever reaction occurs, this assumption is violated. This can be seen from the equation

$$
\mathrm{d} c / \mathrm{d} z=-k c / v
$$

This axial concentration gradient will cause the radicals to be transported down the tube with an additional velocity component $v_{\mathrm{d}}$ given by Fick's first law

$$
J=-D \frac{\mathrm{d} c}{\mathrm{~d} z}=v_{\mathrm{d}} c
$$

where $J$ is the flux (molecules $\mathrm{cm}^{-2} \mathrm{~s}^{-1}$ ) and $D$ is the diffusion coefficient $\left(\mathrm{cm}^{2} \mathrm{~s}^{-1}\right){ }^{78}$ Thus $v_{\mathrm{d}}=D k / v$ and the correct transport velocity for the radicals is $v+v_{\mathrm{d}}$. If $k_{\mathrm{c}}$ is the corrected rate constant and $k$ is the measured value, the correction for axial diffusion is $\left(v+v_{\mathrm{d}}\right) / v$, and

$$
k_{\mathrm{c}}=k\left(1+k D / v^{2}\right)
$$

This result is identical with that obtained earlier ${ }^{73,79}$ by integrating the one-dimensional continuity equation ${ }^{80}$

$$
v \frac{\mathrm{d} c}{\mathrm{~d} z}=D \frac{\mathrm{d}^{2} c}{\mathrm{~d} z^{2}}-k c
$$

This correction will be largest at low pressures (since $D$ $\propto 1 / P$ ) and slow velocities. For example, when $k=100$ $\mathrm{s}^{-1}, D=500 \mathrm{~cm}^{2} \mathrm{~s}^{-1}$, and $v=800 \mathrm{~cm} \mathrm{~s}^{-1}$, the correction is $8 \%$. One normally operates under conditions that minimize the corrections for axial diffusion. When these corrections are not negligible, one must also allow for the effects of other first-order reactions that contribute to the axial concentration gradient such as wall reactions. The appropriate correction for rate constants measured by varying the reaction zone length is

$$
k_{\mathrm{c}}=k\left[1+\frac{\left(k+2 k_{\mathrm{w}}\right) D}{v^{2}}\right]
$$

The flow tube analysis assumes that there are no radial concentration gradients. There are two factors that act to reduce the concentration of radicals near the wall. The first is the wall reaction. The second factor is the slow speed of the gas near the walls gives the reactants in that region a longer residence time than the fast moving radicals at the center. Under ideal (low pressure) conditions, diffusion will maintain a uniform radial profile. However, as the pressure is increased and diffusion becomes less effective the radical concentration will develop a parabolic profile. Rate constants measured under this condition will be in error if the average transport velocity for the radical is assumed to be the gas flow velocity. When the radial concentration profile is a known function of $r, c(r)$, and is constant along the length of the reaction zone, the correct average transport velocity, $v_{\mathrm{T}}$, can be calculated

$$
v_{\mathrm{T}}=\frac{2 \pi \int_{0}^{R} c(r) v(r) r \mathrm{~d} r}{2 \pi \int_{0}^{R} c(r) r \mathrm{~d} r}
$$

The flowing afterglow is an interesting example of a system with an analysis of this type. Here the reactive species are ions which are destroyed by every collision with the reactor wall $(\gamma=1)$. The resultant ion transport velocity has been calculated using a variety of different methods ${ }^{81-83}$ to obtain the radial profile. $v_{\mathrm{T}}=1.6 \mathrm{v}$ under low pressure, diffusion-controlled conditions. Rajotte ${ }^{84}$ has used optical methods to measure the radial profile of metastable neon atoms $(\gamma=1)$ at pressures from 0.1 to 5 torr. He observes the expected transition from a zero order Bessel type distribution at low pressures to a Gaussian type distribution at higher pressures.

Kaufman ${ }^{73}$ derived a formula for calculating the approximate radial concentration gradient for $\gamma<<1$. His result is

$$
\frac{c_{\mathrm{a}}-c_{\mathrm{w}}}{c} \simeq \frac{R^{2}}{8 D}\left(k+3 k_{\mathrm{w}}\right)
$$

where $c_{\mathrm{a}}, c_{\mathrm{w}}$, and $c$ are the axial, wall, and average radical concentrations, respectively. Thus, the concentration gradient is inversely dependent on the diffusion coefficient and directly proportional to the square of the tube radius. Both the homogeneous reaction and the wall reaction are 
TABLE II: Errors in Flow Tube Kinetic Measurements

\begin{tabular}{ll}
\hline source & typical range \\
\hline flow parameters & $\pm(5-10 \%)$ \\
pressure gradient & $\pm 15 \%$ \\
axial concentration & $-(1-20 \%)$ \\
gradient & $-(<100 \%)$ \\
radial concentration & \\
gradient & +
\end{tabular}

important but the wall loss is more critical. Equation 19 is useful to estimate the pressure regime where radial gradients become significant.

There have been numerous papers that evaluate the effects of diffusion and kinetics in a flow reactor. The usual starting point is the continuity equation

$$
2 v\left(1-\frac{r^{2}}{R^{2}}\right) \frac{\partial c}{\partial z}=D \frac{1}{r} \frac{\partial}{\partial r} r \frac{\partial c}{\partial r}+D \frac{\partial^{2} c}{\partial z^{2}}-k c
$$

The first term is for flow or convective transport, the second term is for radial diffusion, the third term is for axial diffusion, and the final term is for reaction. Poirier and $\mathrm{Carr}^{85}$ have presented an interesting numerical analysis of the high pressure regime under conditions where axial diffusion may be neglected. They solve the continuity equation for first- and second-order homogeneous reactions and first-order wall reaction coupled with radial diffusion. They derive correction factors for the transport velocity for a variety of different conditions including detection geometry. They demonstrate that detectors that sample on axis, average along a diameter, or average across the flow tube cross section give different results at high pressures.

Ogren ${ }^{86}$ has also developed an analysis that considers both homogeneous and heterogeneous first-order reactions with radial concentration gradients. He gives a method for correcting rate data.

Since the correction factor for radial concentration gradients depends upon the radial concentration profile, it is not possible to reduce the problem to a simple general solution. The largest possible correction arises when all radicals are concentrated on the reactor axis, in which case, $v_{\mathrm{T}}=2 v$. Therefore the correction factor is always between 1 and 2. Although methods have been derived for correcting high pressure data, there has been no serious effort to apply these corrections.

Westbrook et al. ${ }^{87}$ have developed a technique for studying kinetics in a turbulent flow reactor and report results for studies of high temperature combustion processes. Their work may provide a new direction for flow tube studies in which high flow velocities are employed to give turbulent mixing, thus eliminating difficulties due to diffusion. In principle this method can also be employed to extend the pressure range of low temperature kinetic studies, but it remains to be seen whether it can be applied to the direct measurement of elementary reaction rate constants.

The various sources of errors are summarized in Table II. The sign indicates the direction in which the rate constant is in error. Inaccuracies in the measurement of flow parameters cannot be eliminated, but those from pressure and concentration gradients can be reduced to less than 2 or $3 \%$. Impurities in the reactant gas can cause errors if they are much more reactive than the reactant itself. This error must be eliminated through careful purification and analysis of reactants. A complete analysis of the flow tube method indicates that an overall accuracy of $10-15 \%$ is possible.

In conclusion, it is interesting to see how "state of the art" kinetic measurements compare to this estimated accuracy limit. Watson ${ }^{88}$ has recently reviewed kinetic data for reactions involving chlorine. Because of the importance of these reactions in stratospheric chemistry many laboratories have studied the same reactions using different kinetic techniques. Three reactions from Watson's compilation have been studied recently by four or more laboratories: $(1) \mathrm{OH}+\mathrm{HCl}, 4$ labs, $k \simeq 3.0 \times 10^{-12}$. $\exp (-425 / T) \mathrm{cm}^{3}$ molecule $\mathrm{s}^{-1},(2) \mathrm{Cl}+\mathrm{CH}_{4}, 6$ labs, $k \simeq$ $7.3 \times 10^{-12} \exp (-1260 / T)$; and $(3) \mathrm{Cl}+\mathrm{O}_{3}, 5$ labs, $k \simeq 2.7$ $\times 10^{-11} \exp (-257 / T)$. At least half of the measurements were made using flow tubes. The rate constants for each reaction were averaged and the standard errors were calculated at 298 and $240 \mathrm{~K}$. At both temperatures the agreement is superb. At $298 \mathrm{~K}$ the ratio of the standard error to the mean is 4,8 , and $10 \%$ for reactions $1-3$, respectively. The data for $240 \mathrm{~K}$ give ratios of 14 and $12 \%$ for reactions 2 and 3 . There are only three measurements of reaction 1 at $240 \mathrm{~K}$ and all are within $15 \%$ of the mean. It is not surprising that the low temperature data do not agree as well as the room temperature data since the measurements are near the limit of the temperature range and represent fewer data points. If this comparison can be taken as a fair evaluation of present kinetic data, it indicates that flow tube measurements are within the estimated $10-15 \%$ accuracy range and that there are no significant systematic differences between data obtained using flow tubes and that obtained with other methods.

\section{References and Notes}

(1) E. R. Mosburg, Jr., IEEE J. Quantum Electron., QE9, 843 (1973).

(2) P. J. Crutzen, I. S. A. Isaksen, and J. R. McAfee, J. Geophys. Res., 83, 345 (1978).

(3) J. A. Logan, M. J. Prather, S. C. Wofsy, and M. B. McElroy, Phil. Trans. R. Soc, 290, 187 (1978).

(4) H. B. Palmer and D. J. Seery, Annu. Rev. Phys, Chem, 24, 235 (1973).

(5) The mechanism for the increase in wall removal of radicals at low temperatures has not been explained. Limitations from this effect on a study of chlorine atom reactions below $200 \mathrm{~K}$ were described by M. S. Zahniser, B. M. Berquist, and F. Kaufman, Int. J. Chem. Kinet., 10, 15 (1978).

(6) D. W. Trainor, D. O. Ham, and F. Kaufman, J. Chem. Phys , 58, 4599 (1973).

(7) A. A. Westenberg and N. deHaas, J. Chem. Phys., 46, 490 (1967).

(8) A. A. Westenberg and N. deHaas, J. Chem. Phys., 58, 4061 (1973)

(9) A. Fontijn, S. C. Kurzius, J. J. Houghton, and J. A. Emerson, Rev. Sci. Instrum., 43, 726 (1972); A. Fontijn, W. Felder, and J. J. Houghton Fifteenth Symp. (Int.) Combust., [Proc.], 15th, 775 (1975).

(10) A. Fontijn and W. Felder, J. Phys . Chem., this issue.

(11) C. Anastasi and I. W. M. Smith, J. Chem. Soc., Faraday Trans. 2, 72, 1459 (1976).

(12) D. D. Davis, R. E. Huie, J. T. Herron, M. J. Kurylo, and W. Braun, J. Chem. Phys., 56, 4868 (1972)

(13) R. B. Klemm and L. J. Stief, J. Chem. Phys, 61, 4900 (1974)

(14) B. Reimann and F. Kaufman, J Chem. Phys., 69, 2925 (1978).

(15) P. P. Bemand, M. A. A. Clyne, and R. T. Watson, J. Chem. Soc., Faraday Trans. 1, 69, 1356 (1973).

(16) I. M. Campbell and B. A. Thrush, Trans. Faraday Soc., 64, 1265 (1968).

(17) C. J. Howard and K. M. Evenson, J. Chem. Phys., 64, 4303 (1976)

(18) J. G. Anderson, J. J. Margltan, and F. Kaufman, J. Chem. Phys. 60, 3310 (1974).

(19) J. E. Spencer and G. P. Glass, Chem. Phys., 15, 35 (1976).

(20) C.-L. Lin and F. Kaufman, J. Chem. Phys., 55, 3760 (1971).

(21) A brief summary of the career of R. W. Wood and a list of his publlcations is given by G. H. Dieke, "Blographical Memoirs of Fellows of the Royal Society" Vol. 2, Royal Society, London, 1956, p 327

(22) R. W. Wood, Phil. Mag., 6, 513 (1905).

(23) R. W. Wood and F. L. Mohler, Phys. Rev., 11, 70 (1918).

(24) A. C. G. Mitchell and M. W. Zemansky, "Resonance Radiation and Excited Atoms," Cambridge University Press, New York, 1971, p 31

(25) W. Braun and M. Lenzi, Discuss. Faraday Soc., 44, 252 (1967).

(26) R. W. Wood, Proc. R. Soc., London, Ser. A, 102, 1 (1922).

(27) E. L. Tollefson and D. J. LeRoy, J. Chem. Phys., 16, 1057 (1948)

(28) L. Ellas, E. A. Ogryzlo, and H. I. Schiff, Can. J. Chem., 37, 1680 (1959). 
(29) R. V. Poirier and R. W. Carr, Jr., Rev. Sci. Instrum., 43, 354 (1972)

(30) H. M. Smallwood, J. Am. Chem. Soc., 51, 1985 (1929)

(31) K. F. Bonhoeffer, Z. Phys, Chem. 113, 199 (1924); R. Boehm and K. F. Bonhoeffer, ibid, 119, 385 (1925); K. F. Bonhoeffer and P. Harteck, ibid., A139, 64 (1928).

(32) E. Wrede, Z. Phys., 54, 53 (1929); P. Harteck, Z. Phys. Chem. A 139, 98 (1928)

(33) P. Harteck and U. Kopsch, Z. Phys. Chem., B12, 327 (1931)

(34) F. Kauman, Proc. R. Soc. London, Ser. A, 247, 123 (1958)

(35) F. Kaufman and J. R. Kelso, Symp. (Int.) Combustion., [Proc.], 7th, $53(1958)$

(36) F. Kaufman and F. P. Del Greco, Discuss. Faraday Soc., 33, 128 (1962).

(37) M. A. A. Clyne, "Physical Chemistry of Fast Reactions", Vol. 1, B. P. Levitt, Ed., Plenum Press, New York, N.Y., 1973, pp 245-330.

(38) E. H. Appelman and M. A. A. Clyne, ACS Symp. Ser., No. 66, 3-25 (1978).

(39) M. A. A. Clyne and B. A. Thrush, Proc. R. Soc. London, Ser. A, 269, 404 (1962)

(40) D. J. Bogan, D. W. Setser, and J. P. Sung, J. Phys. Chem, 81, 888 (1977); D. J. Smith, D. W. Setser, K. C. Kim, and D. J. Bogan, J Phys. Chem., 81, 898 (1977).

(41) Mass spectrometry with electron impact lonization originates with J. A. Hipple and D. P. Stevenson, Phys. Rev., 63, 121 (1943).

(42) EPR was invented by Beringer and co-workers: R. Beringer and J. G. Castle, Jr., Phys. Rev., 75, 1963 (1949); E. B. Rawson and R. Beringer, Phys. Rev., 88, 677 (1952).

(43) S. N. Foner and R. L. Hudson, J. Chem. Phys., 36, 2681 (1962)

(44) S. N. Foner and R. L. Hudson, Adv. Chem. Ser., 36, 34 (1962)

(45) L. F. Phillips and H. I. Schiff, J. Chem. Phys., 36, 1509 (1962)

(46) E. A. Albers, K. Hoyermann, $H$. Gg. Wagner, and J. Wolfrum, Symp (Int.) Cornbust., [Proc.], 12th, 313 (1969).

(47) E. E. Daby, H. Niki, and B. Weinstock, Symp. (Int.) Combust., [Proc.], 12 th, 277 (1969)

(48) M. A. A. Clyne and R. T. Watson, J. Chem. Soc., Faraday Trans 1, 70, $1109(1974)$

(49) J.W. Birks, B. Shoemaker, T. J. Leck, and D. M. Henton, J. Chem Phys., 65, 5181 (1977).

(50) G. Poulet, G. LeBrass, and J. Combourieu, J. Chem. Phys , 69, 767 (1978).

(51) I. T. N. Jones and K. D. Bayes, Chem. Phys. Lett., 11, 163 (1971)

(52) I. T. N. Jones and K. D. Bayes, Symp. (Int.) Combust., [Proc.] 14th, 277 (1973).

(53) J. R. Kanofsky and D. Gutman, Chem. Phys. Lett, 15, 236 (1972)

(54) J. R. Kanofsky, D. Lucas, and D. Gutman, Symp. (Int.) Combust., [Proc.], 14th, 285 (1973).

(55) C. E. Kolb and M. Kaufman, Chem. Instrum., 3, 175 (1971).

(56) J. W. Boz:zelli, C. E. Kolb, and M. Kaufman, J. Chem. Phys., 59 3669 (1973).

(57) S. Krongelb and M. W. P. Strandberg, J. Chem. Phys., 31, 1196 (1959).

(58) A. A. Westenberg and N. deHaas, J. Chem. Phys., 50, 707 (1969), and earlier references noted therein.

(59) A. A. Westenberg, Science, 164, 381 (1969).

(60) G. A. Takacs and G. P. Glass, J. Phys. Chem., 77, $1060(1973)$

(61) C.-N. Wei and R. B. Timmons, J. Chem. Phys., 62, 3240 (1975).

(62) P. P. Bemand and M. A. A. Clyne, J. Chem. Soc., Faraday Trans. 2, 72, 191 (1976)

(63) C. J. Howard and K. M. Evenson, J. Chem. Phys., 61, 1943 (1974)

(64) F. C. Fehsenfeld, K. M. Evenson, and H. P. Broida, Rev. Sci. Instrum. 36. 294 (1965).

(65) C. G. Suits, Ed., "The Collected Works of Irving Langmuir", Vol. 1, Pergamon Press, New York, N.Y., 1960, p 103; I. Langmuir and G. M. J. Mackay, J. Am. Chem. Soc., 36, 1708 (1914).

(66) F. Kaufman, Adv. Chem. Ser., 80, 29 (1969).

(67) E. A. Ogryzlo, Can. J. Chem., 39, 2556 (1961)

(68) R. B. Badachhape, P. Kamarchik, A. P. Conroy, G. P. Glass, and J. L. Margrave, Int. J. Chem. Kinet., 8, 23 (1976).

(69) M. A. A. Clyne and B. A. Thrush, Proc. R. Soc. London, Ser. A 275, 544 (1963).

(70) A. A. Westenberg and N. deHaas, J. Chem. Phys ., 46, 490 (1967).

(71) R. J. Cvetanovic, R. P. Overend, and G. Paraskevopoulos, Int. J. Chem. Kinet., Symp. 1, 249 (1975); see also R. J. Cvetanovic, D.
L. Singleton, and G. Paraskevopoulos, J. Phys. Chem., this issue. (72) C. J. Howard and K. M. Evenson, J. Chem. Phys., 64, 197 (1976); 65, 4771 (1976).

(73) F. Kaufman, Frog. React. Kinet. 1, 3-39 (1961)

(74) S. Dushman and J. M. Lafferty, "Scientific Foundations of Vacuum Technique", Wiley, New York, N.Y., 1962, p 82.

(75) J. G. Anderson (private communication) derived a correction term to the Poiseuille equation to describe the effect of an inlet tube of o.d. $R_{1}$ inside a flow tube of i.d. $R$. It is $\left\{1-\left(R_{1} / R\right)^{4}-\left(1-R_{1}{ }^{2} / R^{2}\right) /\right.$ in $\left(R / R_{1}\right)$ ).

(76) M. Gilbert, Combust. Flame, 2, 149 (1958).

(77) G. P. Brown, A. DiNardo, G. K. Cheng, and T. K. Sherwood, J. Appl. Phys., 17, 802 (1946)

(78) Data for diffusion coefficients are found in T. R. Marrero and E. A. Mason, J. Phy's. Chem. Ref. Data, 1, 3 (1972).

(79) P. G. Dickens, R. D. Gould, J. W. Linnett, and A. Richmond, Nature (London), 187, 686 (1960).

(80) W. Jost. "Diffusion in Solids, Liquids, and Gases", Academic Press, New York, N.Y., 1952, p 58

(81) R. W. Huggins and J. H. Cahn, J. Appl. Phys., 38, 180 (1967).

(82) E. E. Ferguson, F. C. Fehsenfeld, and A. L. Schmeltekopf, Adv. At. Mol. Phys., 5, 1 (1969).

(83) R. C. Bolden, R. S. Hemsworth, M. J. Shaw, and N. D. Twiddy, J. Phys. B, 3, 45 (1970)

(84) R. J. Rajotte, Can. J. Spectrosc., 19, 178 (1974).

(85) R. V. Poirier and R. W. Carr, Jr., J. Phys. Chem., 75, 1593 (1971).

(86) P. J. Ogren, J. Phys. Chem., 79, 1749 (1975).

(87) C. K. Westbrook, J. Creighton, C. Lund, and F. L. Dryer, J. Phys. Chem., 81, 2542 (1977).

(88) R. T. Watson, J. Phys. Chem. Ref. Data, 6, 871 (1977).

\section{Discussion}

George BuRns. The principal differences between these two techniques are (1) the methods of initiation of reaction and (2) detection methods of reaction products. In principle, most of the fast gas phase reactions can be studied over a wide temperature range using both of these techniques. In practice, however, one technique will prove to be more appropriate for studying a particular reaction than the other. For example, halogen recombination-dissociation can be studied more easily by flash photolysis because $\mathrm{Cl}_{2}, \mathrm{Br}_{2}$, and $\mathrm{I}_{2}$ absorb flash radiation, and because three body recombination is a relatively slow reaction, during which wall effects may easily interfere. There effects are important in discharge flow reactions and are, generally, insignificant in flash photolysis reactions. On the other hand, recombination of hydrogen atoms can be best studied by the flow-discharge technique, because $\mathrm{H}_{2}$ absorbs only in vacuum $\mathrm{UV}$. In this connection the study of $H$ atom recombination down to $4 K$ by the flow-discharge technique would be particularly important both from the experimental and theoretical view. points. The problem, then, is to determine which technique is most advantageous in studying a particular reaction.

DANIEL W. Trainor. You indicate that wall reactions contribute to the low temperature limit attainable in such measurements. Would you comment on the magnitude of the wall loss as a function of temperature?

CARLETON J. HowaRd. Of course this function depends on the radical and the wall coating. We have not analyzed the dependence but typical results $\mathrm{HO}_{2}$ in a 2.54-cm i.d. $\mathrm{H}_{3} \mathrm{PO}_{4}$ coated tube are $296 \mathrm{~K}, k_{\mathrm{w}}=1-3 \mathrm{~s}^{-1} ; 250 \mathrm{~K}, k_{\mathrm{w}}=5-7 \mathrm{~s}^{-1}$, and $230 \mathrm{~K}, k_{\mathrm{w}}$ $=15-20 \mathrm{~s}^{-1}$. 